\title{
Editorial
}

\section{Islets and Glucose Homeostasis}

\author{
Tien-Jyun Chang, ${ }^{1}$ Gang Xu, ${ }^{2}$ and Jyuhn-Huarng Juang ${ }^{3}$ \\ ${ }^{1}$ Department of Internal Medicine, National Taiwan University Hospital, Taipei 10002, Taiwan \\ ${ }^{2}$ Department of Medicine and Therapeutics, The Chinese University of Hong Kong, Shatin, Hong Kong \\ ${ }^{3}$ Division of Endocrinology and Metabolism, Department of Internal Medicine, \\ Chang Gung University and Chang Gung Memorial Hospital, Taoyuan City 33305, Taiwan
}

Correspondence should be addressed to Tien-Jyun Chang; tjc922@gmail.com

Received 26 January 2015; Accepted 26 January 2015

Copyright ( 2015 Tien-Jyun Chang et al. This is an open access article distributed under the Creative Commons Attribution License, which permits unrestricted use, distribution, and reproduction in any medium, provided the original work is properly cited.

Diabetes mellitus is a chronic progressive metabolic disease, resulting from both insulin resistance and the dysfunction of beta-cells. Beta-cell apoptosis is a crucial pathophysiology leading to diabetes [1]. Aberrant immune system leads to destroying of beta-cells occurring in type 1 diabetes. Infiltration of immune cells around beta-cells and attack of betacells by cytokines or chemokines through upregulating the proapoptotic molecule Bid and subsequently the release of cytochrome $\mathrm{c}$ from mitochondria contributed to apoptosis. Fas/FasL and TNF pathways also elicit the same downstream molecules as the above-mentioned apoptotic pathway [2]. Unlike type 1 diabetes, metabolic disorders mainly cause type 2 diabetes, such as chronic glucotoxicity, lipotoxicity, and endoplasmic reticulum (ER) stress $[3,4]$. Apoptosis in pancreatic beta-cells is observed in response to various stimuli such as glucose, cytokines, free fatty acids, leptin, islet amyloid polypeptide, ER stress, and sulfonylureas [4, 5]. Regardless of the underlying cause of the disease, insufficient betacell mass leads to dependence on exogenous insulin for blood glucose regulation. The morbidities associated with diabetes are significant. The knowledge about pancreas or islets transplantation and factors attributing to changing the secretory function and/or mass of islet beta-cells might help to develop a novel treatment to diabetes.

The past 15-20 years has seen a dramatic increase in the prevalence of T2D in children and adolescents [6-8]. Type 2 diabetes is generally believed to be a polygenic disorder, with disease development being influenced by both hereditary and environmental factors [9]. Support for the role of genetic factors comes from epidemiological evidence that type 2 diabetes in youth is most common in individuals from racial groups with a high prevalence of diabetes and in individuals with a strong family history [10]. A search for the contribution of certain candidate genes in the early onset type 2 diabetes is mandatory for further understanding of pathogenesis of type 2 diabetes in childhood. In this issue, Y.-D. Jiang et al. reported that E23K polymorphism of the KCNJ11 gene contributed to an increased risk for type 2 diabetes in schoolaged child and adolescence. K23-allele-containing genotypes conferring increased plasma insulin level during OGTT in normal subjects. However, the diabetic subjects with the K23allele-containing genotypes had lower fasting plasma insulin levels after adjustment of age and BMI percentiles.

T2DM is a multifactorial metabolic disease mainly characterized by hyperglycemia [11], but before the occurrence of overt hyperglycemia, peripheral insulin resistance leads to compensatory insulin hypersecretion by pancreatic islets [12]. A. P. O. Protzek et al. reported that augmented $\beta$-cell function and increased $\beta$-cell mass developed in response to the glucocorticoid-induced insulin resistance involve inhibition of the islet AS160 protein activity.

Recently, human islet transplantation has achieved insulin independence in type 1 diabetes and the success rates have been markedly improved [13]. However, most successful cases need 2 or more implants and the long-term follow-up shows their insulin independence declines with time $[14,15]$. Therefore, the critical issue in clinical islet transplantation is to further improve and maintain its successful rate. J.-H. Juang et al. reported that posttransplant DPP-4 inhibition with MK0431 in the diabetic recipient with a marginal number of islets 
is not beneficial to transplantation outcome or islet grafts. We cannot exclude the possibility that higher dose of MK0431 or more islets graft may have beneficial effects on the outcome of islet transplantation. M. A. Kanak et al. reviewed recent advances in understanding the role of inflammation in islet transplantation and development of strategies to prevent damage to islets from inflammation. Details on cell signaling pathways in islets triggered by cytokines and harmful inflammatory events during pancreas procurement, pancreas preservation, islet isolation, and islet infusion are presented. The authors also discussed several potent anti-inflammatory strategies that show promise for improving islet engraftment.

Type 1 diabetes is characterized by the progressive loss of pancreatic beta-cells caused by autoimmune attack [16]. Although beta-cell mass is markedly diminished in longstanding type 1 diabetics, residual beta-cells can be detected and new beta-cell formation may occur in these patients several decades after the disease onset [17]. This observation has led to researches to induce remission of diabetes by targeting beta-cell autoimmunity and regeneration. J.-H. Juang et al. reported that before the onset of autoimmune diabetes, alltrans-retinoid acid (ATRA) and exendin-4 treatment alone preserves pancreatic beta-cells; ATRA and ATRA plus exendin- 4 treatment delays the onset of autoimmune diabetes. However, after the onset of autoimmune diabetes, ATRA and/or exendin-4 treatment is unable to reverse hyperglycemia or improve survival.

\section{Tien-Jyun Chang Gang Xu Jyuhn-Huarng Juang}

\section{References}

[1] T. Mandrup-Poulsen, " $\beta$-cell apoptosis: Stimuli and signaling," Diabetes, vol. 50, supplement 1, pp. S58-S63, 2001.

[2] H. E. Thomas, M. D. McKenzie, E. Angstetra, P. D. Campbell, and T. W. Kay, "Beta cell apoptosis in diabetes," Apoptosis, vol. 14, no. 12, pp. 1389-1404, 2009.

[3] M. Cnop, N. Welsh, J.-C. Jonas, A. Jörns, S. Lenzen, and D. L. Eizirik, "Mechanisms of pancreatic $\beta$-cell death in type 1 and type 2 diabetes: many differences, few similarities," Diabetes, vol. 54, supplement 2, pp. S97-S107, 2005.

[4] S. C. Lee and S. Pervaiz, "Apoptosis in the pathophysiology of diabetes mellitus," The International Journal of Biochemistry \& Cell Biology, vol. 39, no. 3, pp. 497-504, 2007.

[5] M. Y. Donath, D. M. Schumann, M. Faulenbach, H. Ellingsgaard, A. Perren, and J. A. Ehses, "Islet inflammation in type 2 diabetes: from metabolic stress to therapy," Diabetes Care, vol. 31, supplement 2, pp. S161-S164, 2008.

[6] R. Kahn, “Type 2 diabetes in children and adolescents," Diabetes Care, vol. 23, no. 3, pp. 381-389, 2000.

[7] D. Dabelea, R. A. Bell, R. B. D’Agostino Jr. et al., "Incidence of diabetes in youth in the United States," The Journal of the American Medical Association, vol. 297, no. 24, pp. 2716-2724, 2007.

[8] H. Dean, "NIDDM-Y in first nation children in Canada," Clinical Pediatrics, vol. 37, no. 2, pp. 89-96, 1998.

[9] K. S. Polonsky, J. Sturis, and G. I. Bell, "Non-insulin-dependent diabetes mellitus-a genetically programmed failure of the beta cell to compensate for insulin resistance," The New England Journal of Medicine, vol. 334, no. 12, pp. 777-783, 1996.

[10] Ó. Rubio-Cabezas and J. Argente, "Current insights into the genetic basis of diabetes mellitus in children and adolescents," Journal of Pediatric Endocrinology and Metabolism, vol. 21, no. 10, pp. 917-940, 2008.

[11] L. F. Rezende, G. J. Santos, J. C. Santos-Silva, E. M. Carneiro, and A. C. Boschero, "Ciliary neurotrophic factor (CNTF) protects non-obese Swiss mice against type 2 diabetes by increasing beta cell mass and reducing insulin clearance," Diabetologia, vol. 55, no. 5, pp. 1495-1504, 2012.

[12] G. C. Weir and S. Bonner-Weir, "Five of stages of evolving $\beta$ cell dysfunction during progression to diabetes," Diabetes, vol. 53, supplement 3, pp. S16-S21, 2004.

[13] A. M. J. Shapiro, J. R. T. Lakey, E. A. Ryan et al., "Islet transplantation in seven patients with type 1 diabetes mellitus using a glucocorticoid-free immunosuppressive regimen," The New England Journal of Medicine, vol. 343, no. 4, pp. 230-238, 2000.

[14] E. A. Ryan, B. W. Paty, P. A. Senior et al., "Five-year follow-up after clinical islet transplantation," Diabetes, vol. 54, no. 7, pp. 2060-2069, 2005.

[15] A. M. J. Shapiro, C. Ricordi, B. J. Hering et al., "International trial of the Edmonton protocol for islet transplantation," The New England Journal of Medicine, vol. 355, no. 13, pp. 1318-1330, 2006.

[16] G. S. Eisenbarth, “Type I diabetes mellitus. A chronic autoimmune disease," The New England Journal of Medicine, vol. 314, no. 21, pp. 1360-1368, 1986.

[17] J. J. Meier, A. Bhushan, A. E. Butler, R. A. Rizza, and P. C. Butler, "Sustained beta cell apoptosis in patients with long-standing type 1 diabetes: indirect evidence for islet regeneration?" Diabetologia, vol. 48, no. 11, pp. 2221-2228, 2005. 


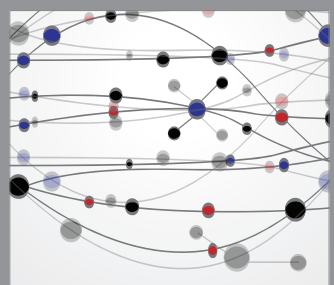

The Scientific World Journal
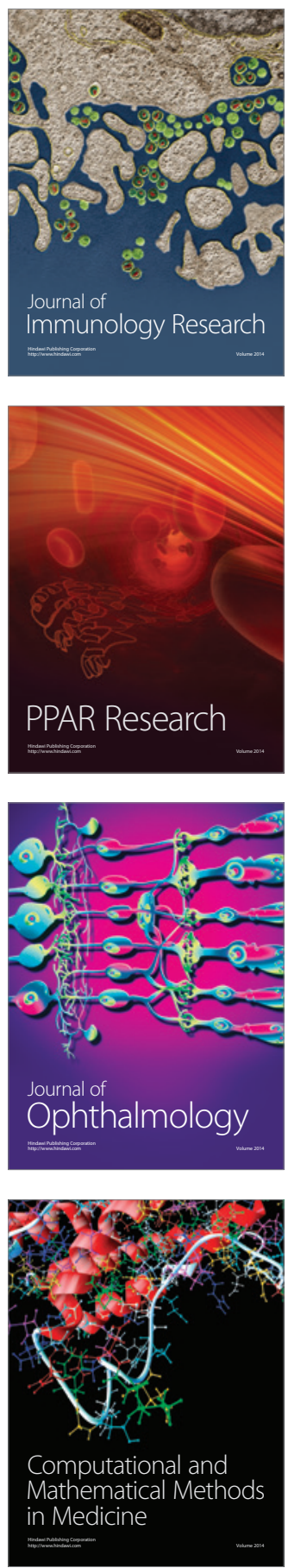

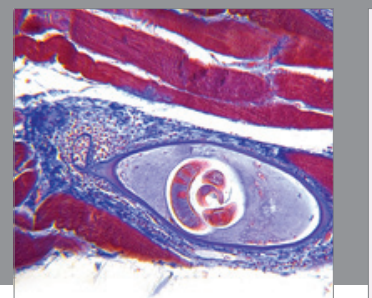

Gastroenterology

Research and Practice
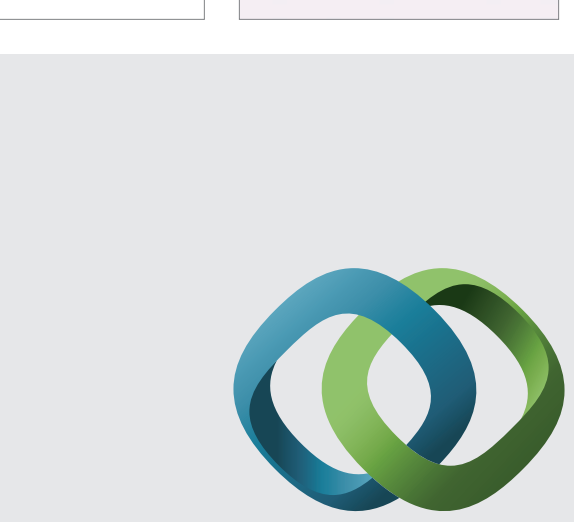

\section{Hindawi}

Submit your manuscripts at

http://www.hindawi.com
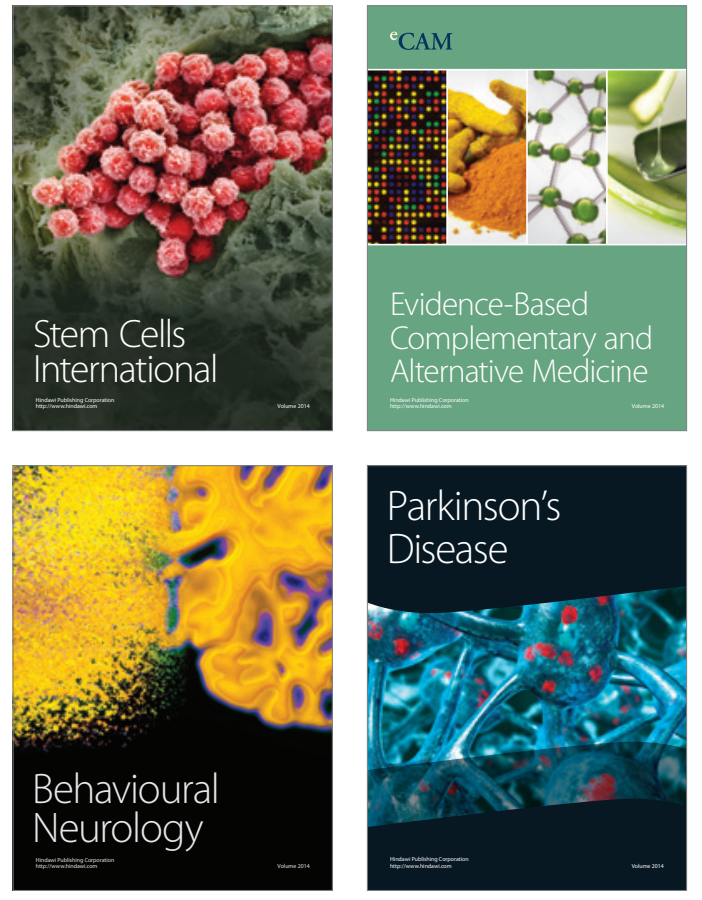
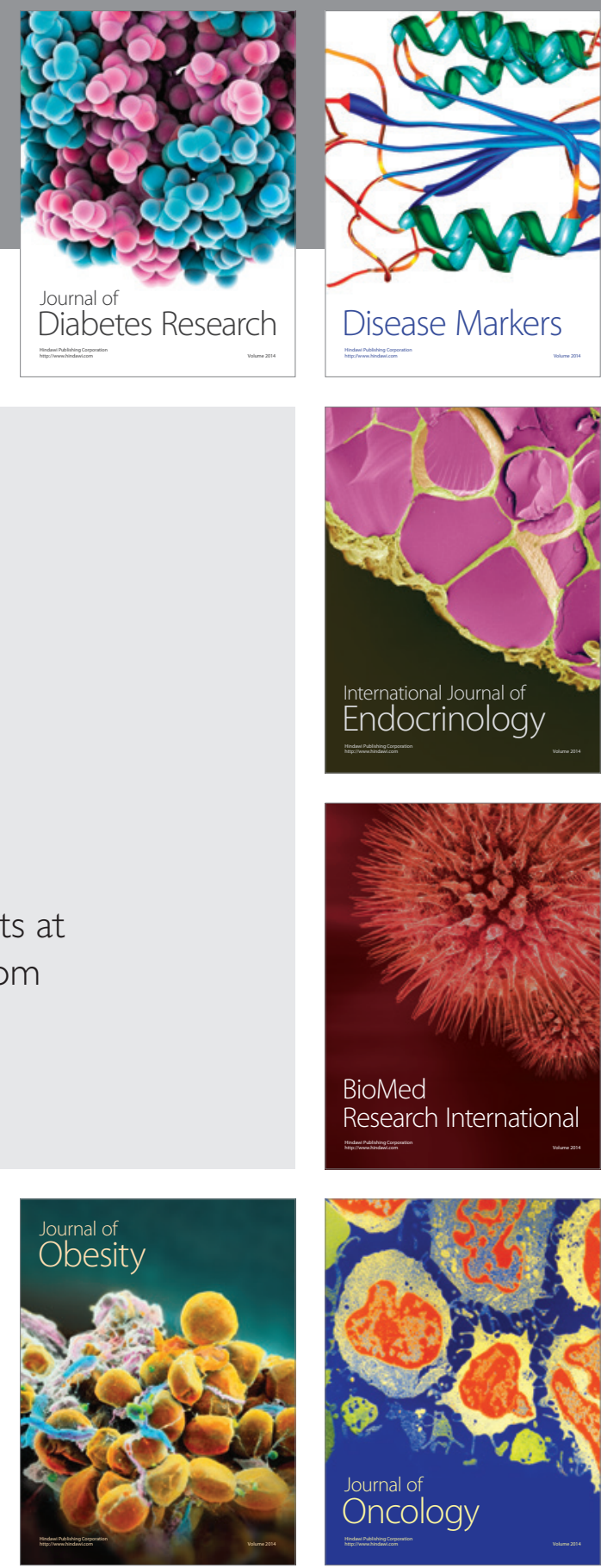

Disease Markers
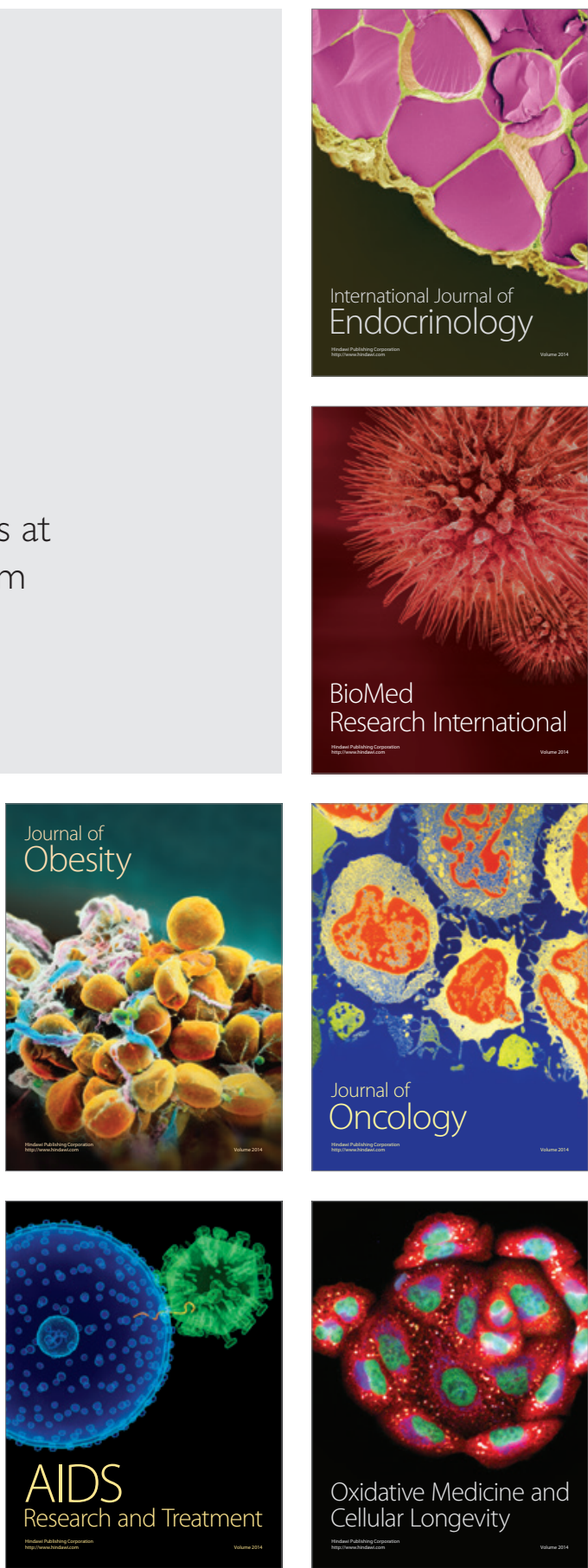